\title{
UNA CURIOSA FORMA ELEMENTAL DE ARQUITECTURA PIONERA RURAL EN MAGALLANES
}

MATEO MARTINIC B.

\section{RESUMEN}

Se informa sobre el hallazgo de una forma arquitectónica elemental para uso como vivienda rural ocasional.

PALABRAS CLAVES: Arquitectura, Magallanes, vivienda.

\section{A CURIOUS ELEMENTAL FORM OF RURAL PIONEER ARCHITECTURE IN MAGALLANES}

\begin{abstract}
The finding of an elemental architectonic form for use as occasional rural house is informed.

KEY WORDS: Architecture, Magallanes, house.

Los sectores periféricos del ecúmene magallánico situados en general hacia el occidente, sudoccidente y sur del mismo, se corresponden con zonas de relieve montuoso y abrupto, de mayor precipitación de agua y nieve y, por consecuencia, con una generosa cobertura vegetal con predominio de las especies forestales. Estos terrenos fronterizos del ecúmene han conformado desde un principio frentes de penetración colonizadora, habitualmente ásperos y, durante mucho tiempo, difícilmente accesibles. En ellos, por tanto, la presencia humana ha sido, como es, más bien ocasional y motivada

principalmente por circunstancias propias de explotaciones tales como la crianza de ganado mayor y la explotación forestal.

Desde el punto de vista del asentamiento humano, aunque tales presencias han llevado a la construcción de habitaciones en forma para el debido resguardo de sus moradores, generalmente viviendas pequeñas conocidas como "puestos", ha sido frecuente en la historia colonizadora la erección de reparos o cobijos de circunstancias, en particular cuando se ha tratado de actividades únicamente ocasionales (arreos) o temporales (corte de madera) como son las propias de esos sitios periféricos.
\end{abstract}

\section{INTRODUCCION}


Por lo tanto esas construcciones han tenido un carácter elemental y precario en el que la madera ha sido la materia prima esencial, siempre disponible, bien mediante el corte de troncos delgados o ramas, o la obtención de piezas por el rajado longitudinal de troncos de mayor diámetro ("rajones"), contándose para ello con el hacha como única y versátil herramienta $y$, de modo excepcional, con la sierra de mano o corvina.

Estos albergues de ocasión, que procuran un reparo mínimo de la intemperie (lluvia y viento principalmente), han adoptado habitualmente la forma de dos paredes de troncos inclinadas, una contra la otra, que se apoyan sobre una estructura simple conformada por dos postes hincados en el suelo, sobre cuyos extremos superiores, siempre en forma de horqueta por un gancho que se ha dejado para el efecto, sobre los que descansa una vara larga que a su vez sirve de apoyo a los troncos (construcción en "A"). A veces, cuando se ha encontrado un árbol de buen porte $y$ desarrollo, con una rama fuerte y situada a conveniente altura, la pared única de troncos se ha hecho descansar sobre la misma (Fig. 1). Las dimensiones de este albergue, largo y alto, estaban dadas por el número de personas que requerían de cobijo.

Las descritas, con mínimas variaciones en cuanto a complemento (p. ej. alguna protección lateral), son las que todavía suelen encontrarse en los sectores que antaño eran los más alejados y de difícil acceso en las fronteras del ecúmene.

Recientemente (febrero de 2009), en un viaje de conocimiento por el camino en construcción que vincula a Puerto Natales con el distrito del fiordo Obstrucción, encontramos en el sector ubicado entre las estancias "Lago Pinto" y María Sofía", a la vera de vía, una forma curiosa, por única, de la arquitectura elemental pionera de que se trata.

Allí, el ingenio humano aprovechó la presencia de un gran bloque errático ${ }^{1}$ y sirviéndose del mismo como apoyo y reparo parcial y de un poste vertical de unos dos y medio metros de altura, y para hacer descansar sobre su horqueta y la piedra una vara de aproximadamente ocho metros de largo. Sobre esta, es claro, debieron amarrarse posiblemente uno o varios trozos grandes de lona (elemento que solían, como suelen llevar consigo los arrieros), y habilitarse así un satisfactorio cobijo de circunstancias (Figs. 2 y 3 ).

La simple-simplísima en verdad, pues apenas requiere de dos piezas de madera-, conforma de este modo la expresión más elemental de arquitectura rural pionera hasta ahora encontrada en Magallanes.

1 Resto o testimonio del antiguo paso de un glaciar.

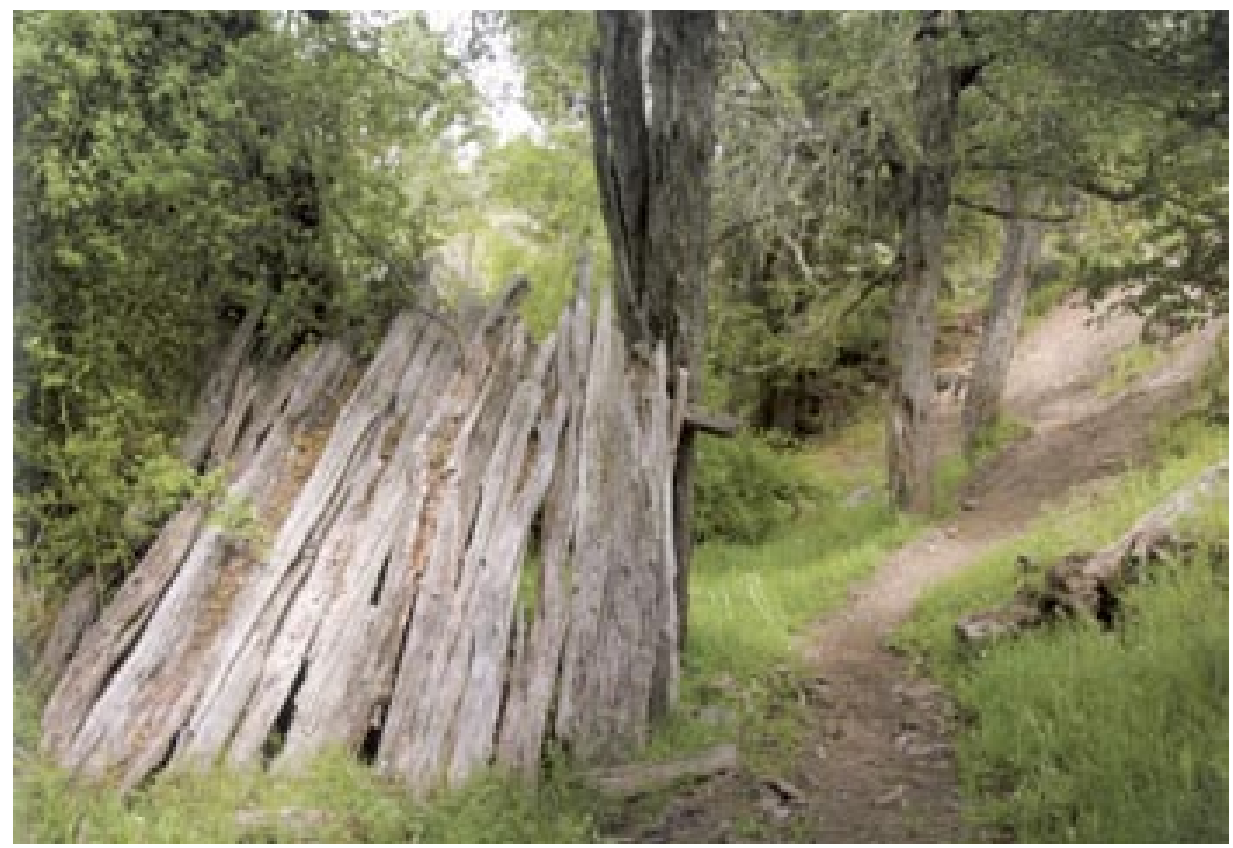

Fig. 1. Rancho construido con empalizada protectora. 


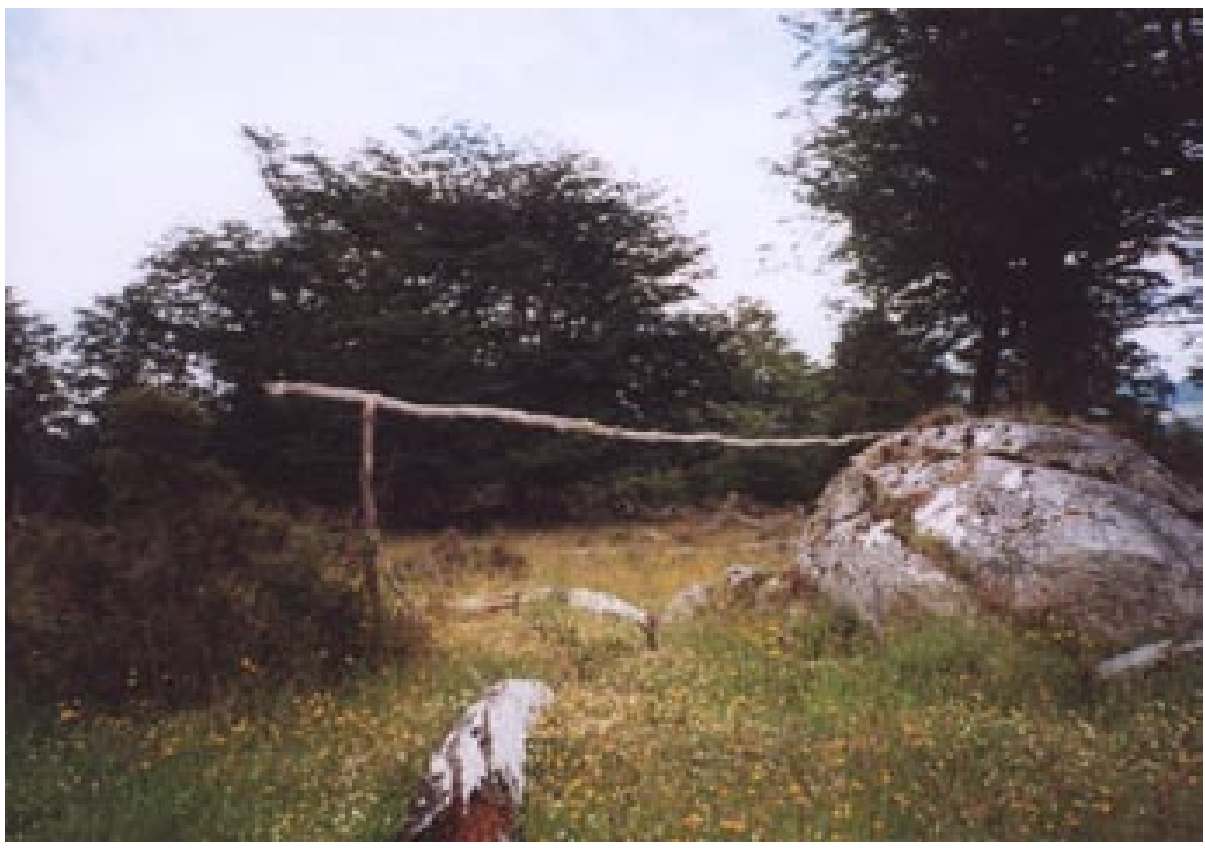

Fig. 2.

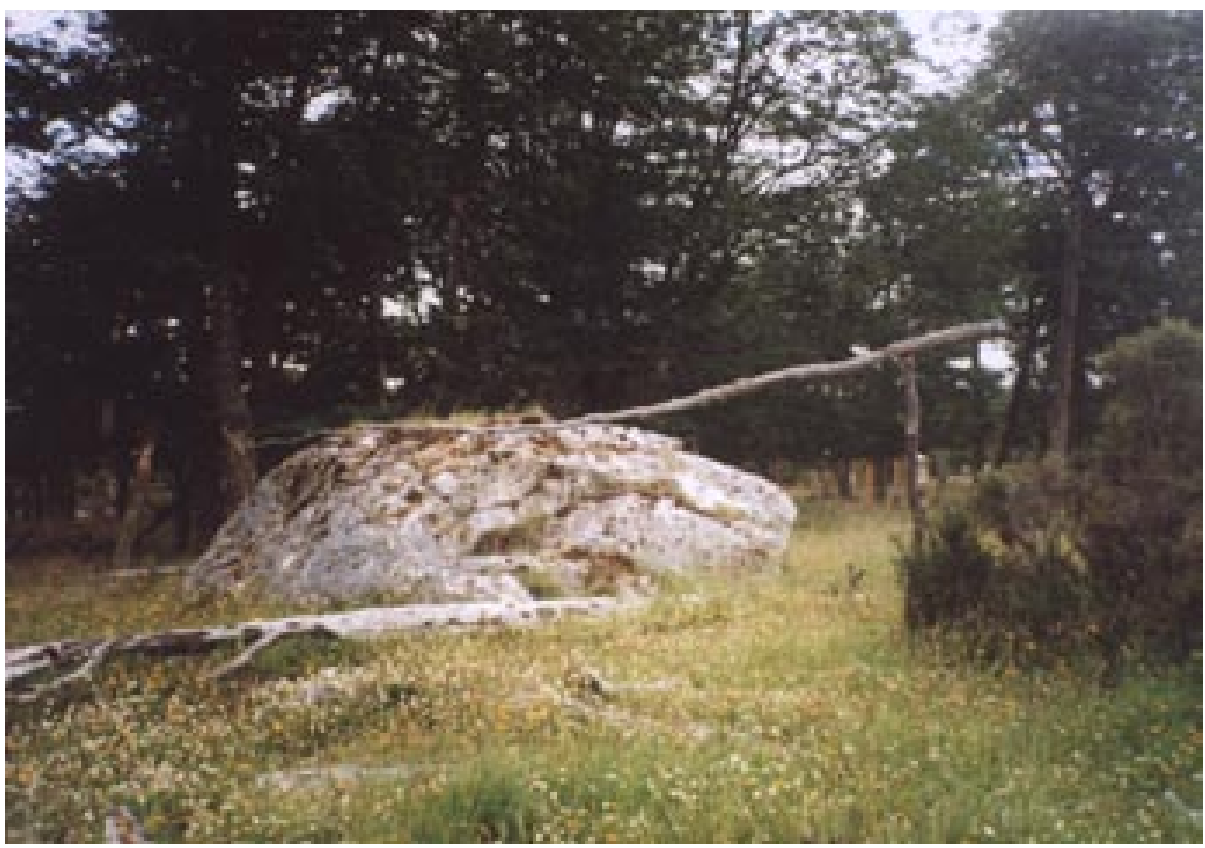

Fig. 3. 
